\title{
Memory sticks
}

Total recall.

\section{Steve Longworth}

The moment I wake I hear Jenny's screams, as loud and clear as they were five years ago; every morning the same terrifying rush as I see Katie's face.

So beautiful. So peaceful. So cold.

I hurry to the bathroom. There are the stacks; the nootropics and the nutraceuticals. I know this routine with the perfect clarity of a religious ritual. I swallow the pageant of smart drugs.

Each cycle begins with Ginkgo biloba to increase cerebral blood flow; then the methylphenidate and modafinil for the dopamine surge. Next will be galantamine and meclofenoxate, then melatonin with fluoxetine to boost neurogenesis in the hippocampus. Finally, there's the supplements; amino acids, vitamin B5, ginseng and fish-oil capsules.

Time to leave.

On the train, as the familiar industrial collage rattles past the window, the screaming starts again, and I see Katie's beautiful, cold, dead face. Again.

I met Jenny at university and we partied. The inconvenience of assignments and exams meant cramming late at night. I was burning the candle at both ends. Surfing the net one day, I stumbled across neuroenhancers, pharmaceuticals to improve cognitive ability and concentration, and I joined the online world of amateur brain experimenters. Not the buzz freaks trading information about 'shrooms and other legal highs. This virtual community was full of high-functioning overcommitted people. They sent me stuff to try.

The effect was startling. I could come in late from the pub, wash down some methylphenidate with a strong caffeinated drink and concentrate intensely and productively into the early hours, recalling my notes and lectures with phenomenal clarity.

I got my first-class degree and a job at a top City trading company making serious money. Big money. Loadsamoney. But you have to move fast, to concentrate intently to stay ahead. The London Stock Exchange is a merciless, testosterone-fuelled battle for supremacy in which small competitive advantages produce disproportionate rewards. Cognitive self-enhancement is not discouraged, so long as you keep making money.

The pressure to succeed steadily increased and so did the need to stay alert,

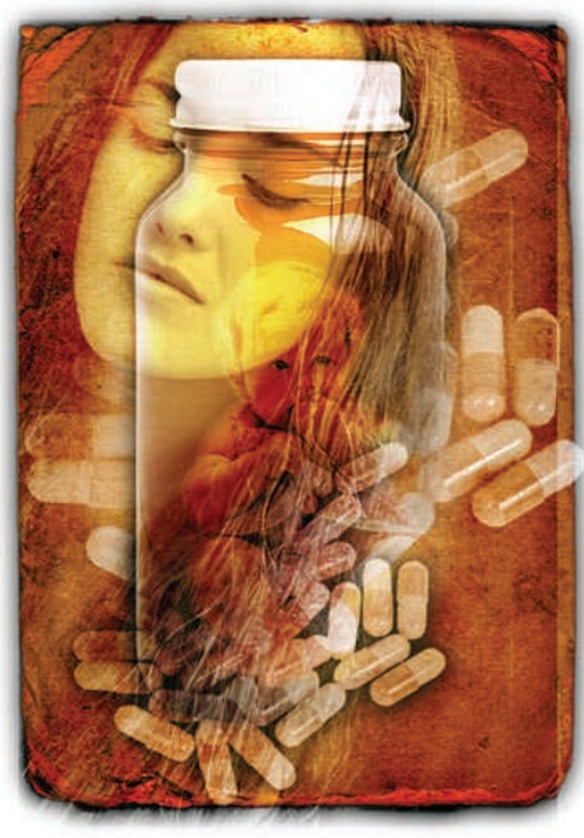

Sudden Infant Death Syndrome is 'every parent's worst nightmare', a momentously awful event reduced to cliché.

Jenny trying to wake Katie. The screaming. Katie lying there; so beautiful; so peaceful; so cold. Jenny hysterical. The paramedics, barely able to hide their own distress; the frantic arrival at the hospital, the brightly lit resuss-room filled with people and machines. The disbelief as the doctor told us that our daughter was dead. Jenny wailing. The small, quiet room where they parked us to absorb the horror. But most of all Jenny screaming, the sound of hell's own fanfare; all stored and replayed with perfect clarity. Every day.

I knew what Jenny was thinking. She had inadvertently taken a cocktail of smart drugs and supplements during her first trimester. Was this the cause of Katie's precocious development and sudden death? We could never bring ourselves to discuss this. The Great Unsaid was a glass wall in our relationship.

Postnatal depression; Jenny refused the antidepressants. I saw the look of horror, guilt and self-loathing that buckled her face when the doctor handed her the prescription. Shortly after that came the first suicide attempt.

I remember Jenny on our wedding day, gorgeous, slim and vibrant. I see her now, shattered, hollowed out and stupefied by the chemical cosh that prevents her from cutting her wrists again.

The Cloister is tranquil and you get a better class of emotional train-wreck. Jenny is now a shuffling zombie, ECT the only remaining option. Connect the brain to the national grid and try to reboot her mind.

Time heals, they say, because over time memories fade, emotions blunt and we adjust, assimilate and move on; but not if the chemicals of memory and emotion are enhanced. Not if memory sticks.

Maybe we should try to fit the world to suit us, rather than the other way around.

Because what makes us human is not our ability to remember.

It is our ability to forget.

Steve Longworth is a full-time GP, part-time hospital specialist and co-author with Stephanie Saunders of Injection Techniques in Orthopaedics and Sports Medicine published by Churchill Livingstone.

Join the discussion of Futures in Nature at go.nature.com/QMAm2a 